\title{
Uma reflexão sobre a saúde e a qualidade de vida de professores de Matemática
}

\author{
A reflection on the health and quality of life of Math teachers
}

\author{
Marilia Beatriz Ferreira Abdulmassih ${ }^{1}$ \\ Darsone Serra Nascimentot
}

\begin{abstract}
Resumo. O estresse está presente na vida de muitas pessoas e possui sintomas bem definidos e possibilidades de tratamento. Algumas pesquisas se referem ao estresse do professor como Síndrome de Burnout, a qual atinge profissionais que trabalham diariamente com pessoas. Este artigo apresenta definições sobre estresse e Síndrome de Burnout, a fim de avaliar a existência de tal esgotamento laboral. Os resultados revelam sintomas de estresse, mas estes não configuram o referido tipo de transtorno. Diante disso, esta investigação pretende identificar os fatores que desencadeiam doenças para professores de matemática e afetam sua qualidade de vida. Parte-se de uma abordagem de pesquisa qualitativa, cuja estratégia de coleta de dados diz respeito a questionários aplicados a 20 professores de matemática da rede de ensino da educação básica de Ituiutaba, Minas Gerais. Com isso, foi feita uma categorização dos dados para análise e considerações finais.
\end{abstract}

Palavras-chave. Qualidade de vida. Síndromes. Doenças. Professores.

\begin{abstract}
Stress is present in the lives of many people and has well-defined symptoms and treatment possibilities. Some researches refer to teacher stress as Burnout Syndrome, which affects professionals who work with people on a daily basis. This article presents definitions about stress and Burnout Syndrome, in order to evaluate the existence of such exhaustion at work. The results reveal symptoms of stress, but these ones do not constitute the referred type of disorder. Therefore, this investigation intends to identify the factors that trigger diseases for mathematics teachers and affect their quality of life. It starts with a qualitative
\end{abstract}

\footnotetext{
${ }^{1}$ Universidade Federal do Piauí - Campus Professora Cinobelina Elvas - CPCE, mariliaabdulmassih@yahoo.com.br

${ }^{2}$ Universidade Estadual de Minas Gerais - UEMG - Unidade Ituiutaba - MG, darsoneleuguto@gmail.com
} 
research approach, whose data collection strategy involves questionnaires applied to 20 mathematics teachers from the educational network of basic education in Ituiutaba, Minas Gerais, Brazil. Hence, a data categorization was made for analysis and final considerations.

Keywords. Quality of life. Syndromes. Diseases. Teachers.

\section{Introdução}

O professor trabalha com o ser humano, o que o leva a cuidar do desenvolvimento do outro com vistas à aprendizagem. Sob o viés da "atividade pedagógica cotidiana, o educador é visto em seu fazer com os alunos, no processo de ensino e aprendizagem" ([10], p. 14).

De fato, o docente é área educacional e possui especificidades próprias em seu trabalho, cujo produto não se abstrai do ato de produção. As atividades laborais são compostas por conhecimentos, ideias, conceitos, valores, atitudes e símbolos que se interagem por meio das relações pedagógicas historicamente determinadas e constituídas entre os homens [11].

No cenário educacional, muitos professores assumem funções em níveis diversos. Mesmo sem ocuparem altos cargos e se aterem ao processo principal de decisões, esses profissionais são imprescindíveis, pois devem exercer, com qualidade e resultados, influência na formação e no desenvolvimento dos alunos que lhe são confiados para receber o reconhecimento esperado. Quando isso não ocorre, começam a surgir os sintomas de estresse no docente.

O trabalho docente vive uma crise de identidade não somente quanto ao conteúdo de informações e conhecimentos, mas também pela competência para gerenciar as crescentes exigências do mundo atual que lhe são impostas. Dessa maneira, os docentes têm se apresentado cada vez menos habilitados e mais insatisfeitos, com baixos índices eficiência e produtividade, o que diminui a autoestima e os deixa doentes e sem perspectiva de melhorias [11].

É notório que a saúde do educador tem sido alvo de discussões, por desenvolver doenças mentais e físicas. Para iniciar a reflexão acerca dos possíveis fatores que desencadeiam enfermidades nesse profissional, faz-se necessário esclarecer inicialmente a expressão "qualidade de vida" que, de acordo com a Organização Mundial da Saúde (OMS), se refere à percepção do indivíduo sobre a própria posição em contextos socioculturais, no sistema de valores de onde vive e nos seus objetivos, expectativas, padrões e preocupações. Como tal conceito é bastante amplo, ele incorpora a saúde física de uma pessoa, o 
estado psicológico, o nível de dependência, as relações sociais, as crenças e a associação com características proeminentes no ambiente [12].

De fato, o estresse é considerado um dos maiores males em decorrência da competitividade no mercado de trabalho e da necessidade de mudanças para se adaptar às novas tendências. Os distúrbios ocasionados por essa doença podem trazer consequências graves e prejudicar tanto o empregado quanto o empregador.

A partir desses conceitos, a escolha do tema "Saúde do professor e qualidade de vida" se justifica pelo fato de perceber que os professores se queixam frequentemente de estarem doentes. Durante as atividades de estágio realizadas no curso de Pedagogia do Instituto de Ciências Humanas do Pontal, na Universidade Federal de Uberlândia (ICHPO/UFU), esse fato chamou a atenção e levou ao estudo da temática.

Dessa forma, o problema que originou o estudo foi: "Quais os fatores que poderão desencadear doenças no professor de matemática da rede de ensino da educação básica de Ituiutaba, Minas Gerais, afetando sua qualidade de vida?". Com isso, objetivou-se identificar os fatores que ocasionam doenças em professores de matemática no exercício de suas funções, o que afeta sobremaneira a qualidade de vida.

Parte-se de uma abordagem de pesquisa qualitativa [8], cuja estratégia de coleta de dados envolve 20 questionários aplicados a professores de matemática que já apresentaram algum tipo de problemas de saúde relacionado ao estresse no exercício da atividade profissional na rede pública de ensino de Ituiutaba/MG. Após aplicar essas ferramentas, foi feita uma categorização dos dados para análise, discussão e considerações finais.

\subsection{As doenças relacionadas aos docentes: uma inserção na litera- tura}

Qualquer processo do indivíduo tem pontos negativos e positivos. No entanto, todos querem gozar de qualidade de vida, independentemente de sua idade, raça, religião e meio sociocultural ou profissão. Nesse caso, a capacidade funcional compreende "a capacidade de o indivíduo manter suas habilidades físicas e mentais requeridas para uma vida independente e autônoma" ([1], p. 40).

Ademais, o referido termo significa, do ponto de vista orgânico, a condição de conseguir fazer os esforços da vida diária. Já sob o viés psicológico, pode ajudar no combate à depressão, ao atuar como catalisador de relacionamento interpessoal, produzir agradável sensação de bem-estar e estimular a autoestima pela superação de pequenos desafetos [5].

A síndrome de Burnout é uma expressão que, em português, significa literalmente "consumir-se em chamas"; logo, o trabalhador perde o sentido de realizar as próprias funções laborais. Portanto, "é um sofrimento do profissional diante do dilema entre o que 
pode realmente fazer e o que efetivamente consegue fazer" ([14], p. 1). Nesse dilema se encontra a raiz das angústias e da dor, em que o professor adoece e pode até desistir da profissão.

Verifica-se que o Burnout "é um tipo especial de stress ocupacional que se caracteriza por profundo sentimento de frustração e exaustão em relação ao trabalho desempenhado" e, normalmente, se instala a partir de expectativas elevadas e não realizadas ([4], p. 16). Funções como professor e médico apresentam mais frequentemente esse transtorno, uma vez que ambos lidam com o público.

O trabalho docente exige contatos interpessoais intensos, por lidar diretamente com outras pessoas em uma função que apresenta carga de emoção relativamente grande, além de ser dotada de grande idealismo. De tal maneira, o professor anseia por autonomia e reconhecimento por parte da população, mas, quando isso não acontece, ele fica mais vulnerável à síndrome.

Constata-se que a síndrome de Burnout ocorre de forma gradual. Nesse processo cumulativo, o início é marcado por pequenos sinais, nos quais o sujeito normalmente não percebe o que ocorre de fato - quando o descobre, já pode ter uma sensação de terror em relação ao trabalho. Tais elementos podem ser notados no Quadro 1:

Quadro 1: Características da síndrome de Burnout.

Entusiasmo e dedicação cedem lugar à
frustração e raiva como resposta a estressores pessoais, ocupacionais e sociais, que, por sua vez, levam
$\Downarrow$
à desilusão quanto às atividades de ensino, trabalhando ainda eficiente, mas mecanicamente, levando à
$\Downarrow$
diminuição da produtividade e da qualidade do trabalho, e depois a
$\Downarrow$
uma vulnerabilidade pessoal cada vez maior, com múltiplos sintomas físicos (dores de cabeça,
hipertensão etc.), cognitivos (“a culpa é dos alunos") e emocionais (irritabilidade, tristeza), os quais,
se não forem tratados,
$\Downarrow$

Fonte: [4], p. 17.

Assim se observam as seguintes fases que se sucedem nessa síndrome ([4], p. 17):

1 - Idealismo: energia e entusiasmo ilimitados;

2 - Realismo: percepção de que as expectativas iniciais eram irrealistas;

3 - Quase-Burnout: frustração e culpabilização dos colegas pelas dificuldades; 
4 - Apatia e Burnout total: sensação de desespero, fracasso e baixa autoestima, abandono do trabalho;

5 - Fenômeno fênix: renascimento do professor em meio ao Burnout, o que nem sempre acontece.

No que tange às características principais, são diagnosticados estes aspectos ([4], p. 17):

Sentimento de insatisfação, desilusão, falta de realização, distanciamento emocional, impotência e apatia; além de alguns outros que nem sempre se manifestam sequencialmente: exaustão emocional, falta de realização pessoal e despersonalização.

Especificamente para o professor, a síndrome de Burnout se caracteriza pela exaustão de recursos emocionais, o que leva a atitudes negativas, distanciamento em relação aos alunos e valorização negativa do papel profissional. No entanto, a exaustão emocional é uma das características que mais aparece nos profissionais da educação.

Aspectos como a correria do dia a dia, a indisciplina, o medo em decorrência da violência e a baixa remuneração são enfrentados por professores e levam ao adoecimento, com sintomas como estresse, depressão e síndrome de Burnout. Convém salientar que, quando a escola passa a ser motivo de constante frustração para o docente, as consequências tendem a ser negativas.

Se houver frustração e impossibilidade de atingir objetivos pessoais, estresse e outros comportamentos negativos se tornam frequentes, como agressão, fuga, esquiva (faltas, absenteísmo, doença), persistência em respostas inoperantes, desvio de atenção e de compromisso, negação do fato, mudanças constantes de plano de ação e de estratégia, falta de adesão ao Projeto Político-Pedagógico (PPP), crítica pela crítica, oposição descabida etc. [18].

Além dos fatores supracitados, as políticas públicas não corroboram o cenário, uma vez que se constata pressões de gestores, governos etc. A competição feroz, a globalização e os programas de qualidade e produtividade, por exemplo, levam o indivíduo ao estresse [9].

A ansiedade pode ser uma fonte poderosa de estresse, visto que o ser humano com essa característica tende a ver o mundo de modo ameaçador, como se houvesse sempre um risco para dar certo. O que representaria somente um desafio para outras pessoas, se torna uma batalha frequente para quem tem ansiedade, pelo fato de o considerarem gigantesco; logo, se estressam mais.

O termo "estresse" foi utilizado pela primeira vez na área da saúde para designar um conjunto de reações específicas, observadas em pacientes que sofriam diversas patologias. Em 1936, definiu-se a reação do estresse como uma síndrome geral de adaptação e, em, 
1974, passou a ser vista como uma resposta não específica do corpo a qualquer exigência [15].

Nesse contexto são encontradas crenças racionais, as quais proporcionam análises realísticas e objetivas dos problemas, além de soluções plausíveis ou até mesmo se adaptar e aceitar uma conjuntura problemática, com condições básicas para o ser humano enfrentar o estresse, resolver problemas e tolerar frustrações. Já as crenças irracionais são uma maneira distorcida e disfuncional de julgar as situações ligadas a tendências de a pessoa julgar a si mesma, o mundo e as pessoas de maneira negativa. "Essas crenças são limitadoras do desenvolvimento humano e normalmente geram frustrações, ansiedade e stress" ([6], p. 36).

Em outras situações, a pessoa pode se frustrar com tanta intensidade ante o não preenchimento de suas expectativas que, muitas vezes, se esquiva dessas tentativas, pois a frustração parece algo "horrível" e "absolutamente insuportável". Outros sujeitos sensíveis à frustração criam um estresse constante para si mesmos, quando algo não acontece do modo como anteciparam [6].

Nota-se que o estresse se dá pelo ritmo de vida das pessoas no mundo contemporâneo e envolve o desgaste emocional e físico, em que pode haver fatores prejudiciais à saúde, mas nem sempre eles são negativos. Alterações podem ocorrer em situações agradáveis que ocasionem algum tipo de prazer à pessoa [2]. Além disso:

\footnotetext{
Os conflitos existentes no ambiente de trabalho podem levar os funcionários ao estresse, porém o próprio causador de tudo pode ser apenas a própria pessoa, dependendo de sua personalidade que estará em evidência através de suas atitudes ([2], p. 124).
}

O autor supramencionado explica também que "o estresse é um processo, não surge num passe de mágica, o seu desenvolvimento depende da resistência de cada pessoa, da sua personalidade, da sua maneira de aceitar as coisas que acontecem" ([2], p. 140).

Conflitos observados no ambiente de trabalho podem levar os funcionários ao estresse, porém, o causador "pode ser apenas a própria pessoa, dependendo de sua personalidade que estará em evidência através de suas atitudes" ([2], p. 124). Considera-se que o comportamento descontrolado de pessoas estressadas é causado por vários aspectos, como a sobrecarga do trabalho, quando há a necessidade de estar atualizado e, por consequência, sob pressão.

São notados casos de sujeitos que se estressam por não conseguirem se relacionar efetivamente com outros indivíduos. Para eles, o relacionamento interpessoal é tedioso e não proporciona algo positivo, por buscarem novidades com frequência; logo, a busca não preenchida passa a ser estressante [6].

Todavia, o estresse não ocorre apenas em pessoas que apresentam essa tendência. Existem casos graves causados por situações que seriam estressantes para qualquer in- 
divíduo, como guerra, sequestro, fome, assalto, sobrecarga de trabalho, perdas sérias, ocupações, conflitos interpessoais, mudança de grande porte, entre outras. Nesse estado condicionado pelo desequilíbrio nos mecanismos fisiológicos do sujeito, em que cada organismo é um sistema vivo que troca informações e matéria entre os ambientes interno e externo [17].

Todo ser humano nasce com a predisposição para se estressar ou não e possui um limite para suportar tensões e dificuldades. Quando a carga estressante se sobressai, o sujeito com ou sem predisposição genética ou constitucional pode ter estresse. Ao se tratar de maneira terapêutica, é importante compreender o tipo de pessoa a ser tratado, e não apenas a doença em si.

Os fatores que causam o estresse são chamados estressores e podem ser de origem externa (situações às quais a pessoa é exposta, como casamento e demissão) ou interna (percepção particular de cada um, frente às experiências da vida); logo, o estresse não se manifesta de forma semelhante e fixa em todos os indivíduos, mas variável, já que depende da subjetividade de cada um [6].

Todos devem ter acesso às informações que podem melhorar a qualidade de vida do ser humano. Para lidar com o estresse, por exemplo, deve-se perceber e eliminar algumas fontes:

\begin{abstract}
As fontes internas estão relacionadas com a maneira de ser do indivíduo, tipo de personalidade e seu modo típico de reagir à vida. Muitas vezes, não é o acontecimento em si que se torna estressante, mas a maneira como é interpretado pela pessoa. Os estressores externos podem estar relacionados com as exigências do dia-a-dia do indivíduo como os problemas de trabalho, familiares, sociais, morte ou doenças de um filho, perda de uma posição na empresa, não concessão de um objetivo de trabalho, perda de dinheiro ou dificuldades econômicas, notícias ameaçadoras, assaltos e violências das grandes cidades, entre outros. Muito frequentemente, o estresse ocorre em função dos diversos tipos de cargos, de ocupação que a pessoa exerce ([7], p. 9).
\end{abstract}

Vale reiterar que as fontes externas são constituídas de elementos recorrentes para os sujeitos e que não são intrínsecos a eles, como vida profissional, falta de dinheiro, brigas, assalto, perdas e falecimentos. Não há somente acontecimentos negativos que dão origem ao estresse, dado que determinados eventos, mesmo que tragam felicidade, podem também exigir adaptações e, por isso, se tornam fontes positivas.

Enquanto isso, as fontes internas se referem a uma "fábrica" particular de estresse, ao próprio modo de ser e agir, bem como a crenças e valores. Os estressores externos são mais fáceis de serem identificados porque são passíveis de inspeção objetiva dos sujeitos - sabe-se, por exemplo, que a pessoa que passou pela morte de um ente querido deve estar sob estresse excessivo. Mas, quando se refere ao que está no ser humano, escondido e, às vezes, dormente, se torna difícil de ser avaliado. A própria pessoa não consegue perceber 
que certas formas de pensar e analisar o mundo podem criar estresse.

A ansiedade é um sentimento difuso de medo, diante de algo que não se sabe o que é exatamente e para o que também não apresenta uma resposta precisa. Quando há medo, a pessoa tende a fugir ou evitar a situação, a exemplo do medo de cachorros; já a ansiedade pode deixar o sujeito parado, sem saber o que fazer.

Por fim, convém salientar que altos níveis de ansiedade frequentes podem deixar as pessoas estressadas. Assim, a ansiedade, o medo e o estresse estão relacionados entre si.

\title{
2 Desenvolvimento
}

Como dito anteriormente, para a realização da pesquisa e em conformidade com os objetivos propostos, e ao problema formulado, optou-se pela abordagem da pesquisa qualitativa [8]. A abordagem qualitativa, é delineada também, pelo contato direto e prolongado do pesquisador com o ambiente e a situação que está sendo investigada. A estratégia de coleta de dados nesse estudo, compreende a aplicação de questionários em 20 professores da rede de ensino de Ituiutaba/MG.

Esse tipo de estudo, no caso a pesquisa qualitativa, pode ser iniciado também pela fase exploratória, que consiste em uma caracterização do problema, do objeto, dos pressupostos, das teorias e do percurso metodológico. Não se pretende resolver de imediato o problema, mas caracterizá-lo a partir de uma visão geral, aproximativa do objeto pesquisado [8].

A pesquisa de campo é uma das etapas da metodologia científica que corresponde à observação [16]. Nesses termos:

\begin{abstract}
A pesquisa de campo é o tipo de pesquisa que pretende buscar a informação diretamente com a população pesquisada. Ela exige do pesquisador um encontro mais direto. Nesse caso, o pesquisador precisa ir ao espaço onde o fenômeno ocorre, ou ocorreu e reunir um conjunto de informações a serem documentadas ([13], p. 169).
\end{abstract}

Foram aplicados questionários a professores que trabalham na rede de ensino da educação básica de Ituiutaba/MG, para identificar aspectos relativos à vivência, à qualidade de vida e às doenças que os afetam. Todos os questionários entregues, num total de 20 , foram devolvidos.

Tal ferramenta metodológica:

Consiste em um conjunto de questões pré-elaboradas, sistemática e sequencialmente dispostas em itens que constituem o tema da pesquisa, com o objetivo de suscitar dos informantes respostas por escrito ou verbalmente sobre o assunto que os informantes saibam informar ou opinar ([3], p. 55). 
O questionário também pode ser definido como a técnica de investigação "composta por um número mais ou menos elevado de questões apresentadas por escrito às pessoas, tendo por objetivo o conhecimento de opiniões, crenças, sentimentos, interesses, expectativas, situações vivenciadas etc.” ([13], p. 169).

Serão considerados os seguintes critérios para a seleção dos sujeitos: as respostas dadas aos questionamentos que poderão auxiliar, analisar e responder o que propõe esta pesquisa; e os aspectos pertinentes à vivência, à qualidade de vida e às doenças que afetam os docentes de matemática da rede pública de ensino de Ituiutaba/MG.

Composto por 16 questões abertas, o questionário foi aplicado a 20 professores que se dispuseram a participar da pesquisa. Destes sujeitos, um respondeu às questões em casa, sem um entrevistador presente (as perguntas eram abertas com espaço para aprofundar respostas). O questionário elaborado era simples e curto, de forma que as respostas obtidas apresentaram uma perspectiva mais generalizada.

Após a aplicação do questionário, os docentes tiveram espaço para relatar qualquer informação ou vivência que adicionasse informações ao estudo e aprofundasse as questões inicialmente tratadas. As perguntas do questionário foram elaboradas com temas prédefinidos, e os professores puderam apresentar, de forma mais clara e livre, suas opiniões e posicionamentos.

Nesse sentido, as questões tiveram como base temas relacionados diretamente à relação entre trabalho e adoecimento, e entre o trabalho do professor e a gestão/organização da escola - por exemplo, foi considerado se a instituição, em algum momento, propunha momentos de relaxamento. Tal ferramenta metodológica de coleta de dados, visou levantar pontos principais sobre o trabalho exercido pelo professor no estabelecimento de ensino, como também questões acerca da saúde e de qualquer fator que poderia desencadear o estresse ou a síndrome de Burnout.

Convém salientar que, por meio da pesquisa de campo, é possível promover a compreensão e obter resultados relativos ao assunto tratado. Os professores que aceitaram participar da investigação receberam as pesquisadoras sem empecilhos.

\section{Análise e discussão}

Com o escopo de identificar os fatores que desencadeiam doenças no professor de matemática e afetam a qualidade de vida no exercício de suas funções, serão elencados aspectos pertinentes à análise e à discussão dos dados.

A partir da (re)leitura e dos dados coletados no questionário, foi possível levantar 3 categorias de análise, desmembradas em tópicos, que respondem à problemática levantada na pesquisa, conforme as seções subsequentes. 


\subsection{Primeira categoria: satisfação no trabalho}

Nesta categoria, visa-se analisar a satisfação no trabalho presente nas respostas dos professores. Eles afirmaram que gostam de dar aulas e estar na escola, mas, quanto ao ambiente de trabalho, citaram que há aspectos negativos que incidem diretamente no trabalho docente.

Quando há satisfação no que se faz, em um local que não prejudica a capacidade funcional do sujeito, combate-se a depressão, "atuando como um catalisador de relacionamento interpessoal, produzindo agradável sensação de bem-estar, e estimulando a autoestima pela superação de pequenos desafetos" ([5], p. 10). Assim, o sujeito que trabalha onde se tem prazer no que faz pode evitar desgastes e, consequentemente, doenças mentais.

Vale ressaltar que as pesquisadoras se depararam com um ponto positivo no que diz respeito ao combate à depressão. Isso se deve ao fato de todos os entrevistados se mostrarem satisfeitos quanto à função exercida no estabelecimento de ensino.

\subsection{Segunda categoria: desgaste físico e jornada excessiva de traba- lho}

Nesta categoria, visou-se avaliar como os professores estavam expostos a fatores que causassem estresse. Eles foram questionados sobre a satisfação de trabalhar em vários lugares; exercer outra atividade além da docência; se a jornada de trabalho era muito longa; e o grau de satisfação com a remuneração recebida.

Todas informaram que trabalham (ou trabalharam) em mais de uma instituição ao mesmo tempo, por não estarem totalmente satisfeitos com a remuneração recebida. Relataram também que, por conta da longa jornada excessiva, sofriam com desgastes físicos, a exemplo do cansaço; e mentais, como estresse. Diante disso, infere-se que os conflitos existentes no ambiente laboral podem levar os funcionários ao estresse [2].

Verifica-se que o docente se considera um sujeito cansado, desgastado e exaustado emocionalmente devido a longas jornadas de trabalho para tentar suprir a má remuneração. Esta última pode ser mais um elemento que contribui para o surgimento do estresse, assim como os conflitos que ocorrem ambiente de trabalho [2].

\subsection{Terceira categoria: fatores que podem desencadear doenças físi- cas e/ou mentais nos professores}

Esta categoria tem por objetivo verificar os fatores que podem desencadear doenças físicas e/ou mentais nos professores, como indisposição e falta de ânimo. O principal motivo in- 
formado por eles foi a carga horária extensa, pois, além de lecionarem na escola, precisam corrigir trabalhos, elaborar provas e preencher diários em suas residências.

Devido ao excesso de trabalho, falta disposição para lecionar. Alguns docentes relataram que a atividade profissional exercida, apesar de ser gratificante, se torna desgastante conforme os elementos citados acima. Outros afirmaram que a profissão traz esgotamento constante devido a fatores externos [6] que, além de desencadear estresse, podem gerar Síndrome de Burnout, como carga horária extensa, falta de disposição, desânimo, automatismo e esgotamento.

Outro fator relevante é a falta de auxílio do aparelho estatal quanto à indisciplina de determinados alunos. Foi salientado que os compromissos acadêmicos (reuniões, relatórios e projetos) incidem nesse contexto, o que torna improdutivo o trabalho docente e modifica o ritmo das atividades diárias, com pressão constante. Indica-se que, "quando a escola passa a ser motivo de frustração, as consequências tendem a ser negativas, resultando em impossibilidade de atingir metas ou objetivos pessoais, gera-se o stress e outros comportamentos negativos" ([18], [n.p.]).

A baixa remuneração e as más condições de trabalho também foram fatores citados como influências ao desgaste físico e emocional. Nesse entremeio se inserem elementos como "a competição feroz, a globalização, os programas de qualidade, produtividade e tantos outros que deixam o indivíduo estressado" ([9], p. 29).

$\mathrm{Na}$ avaliação final do questionário, deparou-se com inúmeros fatores que desencadeiam o estresse, como:

- Carga horária excessiva;

- Baixa remuneração;

- Cansaço mental;

- Cansaço físico;

- Indisposição mediante a carga de trabalho extensa;

- Falta de ânimo;

- Indisciplina dos alunos;

- Competição com os demais colegas;

- Falta de auxílio do aparelho estatal. 
Em síntese, o estresse se torna latente devido a conflitos existentes no ambiente de trabalho, com processos vividos no dia a dia, ou seja, os fatores são cumulativos. Ressalva-se que o estresse, por ser um processo, não surge em um "passe de mágica" [2].

Ademais, constatou-se que os docentes se sentem satisfeitos com a profissão exercida. Entretanto, as dificuldades que levam ao esgotamento profissional foram citadas por todos os entrevistados, sobretudo em relação ao estresse e à síndrome de Burnout. Esses elementos deveriam ser considerados por entidades governamentais, para que os professores sejam auxiliados e exerçam suas funções de maneira efetiva.

\section{Algumas considerações}

Neste trabalho que envolveu profissionais da área da educação, mais especificamente professores de matemática da rede pública de ensino de Ituiutaba/MG, foi constatado que o estresse é uma doença da vida moderna fundamentalmente ligada a fatores psicológicos. Para ele ocorrer, são necessários o estressor e uma personalidade propícia a desencadear o desgaste emocional.

Notou-se também que o estresse e a síndrome de Burnout são doenças que atingem profissionais de áreas como saúde, educação, entre outras. Conhecer as características da doença, os sintomas e as consequências não é o suficiente; logo, esta pesquisa tentou verificar esses elementos in loco, o que contribui para o campo de investigação.

A prevenção do estresse e do Burnout em docentes resulta em um ensino de qualidade, sem prejuízos nas relações entre professor e alunos e nas instituições de ensino. Por isso, a realização de pesquisas sobre doenças mentais no contexto educacional é essencial, para reunir subsídios que fundamentem programas voltados aos docentes e a uma melhor qualidade de vida para esses profissionais, com reflexos positivos no processo de ensino e aprendizagem.

Diante disso, as instituições escolares poderiam auxiliar os professores ao proporcionar atividades que aliviassem as tensões para evitar patologias diversas, a exemplo do estresse. Como a profissão docente é uma das mais desvalorizadas e negligenciadas no contexto atual, as baixas remunerações, as longas jornadas de trabalho, a indisciplina e a falta de respeito de alunos, governantes e sociedade impactam decisivamente no trabalho exercido nas instituições de ensino. Tais elementos podem levar o professor à insatisfação, ao desestímulo e ao sofrimento psíquico, em que se sobressai a síndrome de Burnout para, enfim, deixar a profissão.

Por meio do presente estudo, foi possível verificar que a atividade profissional acadêmica é estressante, em que há sofrimento e repercussões negativas na saúde física, mental e no desempenho docente. Os processos de adoecimento dos professores das escolas 
pesquisadas não são muito evidentes e, de certa forma, foram mascarados por eles nas entrevistas, provavelmente em virtude da organização da escola. Todavia, é notável a existência de processos de adoecimento, mesmo que em menores proporções, e a instituição de ensino influencia nesse contexto.

Destarte, ao avaliar o grupo de professores na cidade pesquisada, conclui-se que há sintomas de estresse sobre o trabalho docente. Há a hipótese de que o trabalho docente é exaustivo, no qual as características patogênicas podem estar associadas a aspectos socioculturais ou institucionais. Assim, os profissionais se sentem desestimulados diante dos processos laborais, o que pode acarretar na síndrome de Burnout a médio e longo prazo.

\section{Referências}

[1] BRASIL. Ministério da Saúde. Secretaria de Assistência à Saúde. Manual para a organização da atenção básica. Brasília, 1999.

[2] CARVAlHO, A. V. de; SERAFIM, O. C. G. Administração de Recursos Humanos. São Paulo: Biblioteca Pioneira de Administração e Negócios, 1995. v. 2.

[3] CHIZZOTTI, A. Pesquisa qualitativa em Ciências Humanas e Sociais. 9. ed. São Paulo: Cortez, 2008.

[4] COUTINHO, L. dos R. Gestão e saúde do professor. 2007. Trabalho de Conclusão de Curso (Graduação) - Universidade Federal de São Carlos, São Carlos, 2007.

[5] FRUTUOSO, D. A terceira idade na universidade: relacionamento entre gerações no $3^{\circ}$ milênio. Rio de Janeiro: Editora Ágora da Ilha, 1999.

[6] LIPP, M. E. N. (Org.). O stress no Brasil: pesquisas avançadas. Campinas: Papirus, 2004.

[7] LIPP, M. E. N.; MALAGRIS, L. N. O stress emocional e seu tratamento. In: RANGE, B. (Org). Psicoterapias cognitivo-comportamentais. Campinas: Psy II, 2004.

[8] LÜDKE, M.; ANDRÉ, M. Pesquisa em educação: abordagens qualitativas. São Paulo: EPU, 1986.

[9] MARINS, L. Livre-se dos “corvos”. São Paulo: Harbra, 2013.

[10] MILL, D.; RIBEIRO, L. R. C.; OlIVEIRA, M. R. G. (Orgs.). Polidocência na educação a distância: múltiplos enfoques. São Carlos: EdFSCar, 2010. 
[11] OLIVEIRA, N. T. de. Somatização e sofrimento no trabalho. Textos \& Contextos, Porto Alegre, ano II, n. 2, [n.p.], 2003.

[12] OMS. Organização Mundial da Saúde. Conceituando Deficiência. 1948.

[13] PIANA, M. C. A pesquisa de campo: a construção do perfil do assistente social no cenário educacional. São Paulo: Editora Unesp; Cultura Acadêmica, 2009.

[14] ROSA, C.; CARLOTTO, M. S. Síndrome de Burnout e satisfação no trabalho em profissionais de uma instituição hospitalar. Revista da SBPH, v. 8, n. 2, p. 1-15, 2005.

[15] SELYE, H. Stress, a tensão da vida. Nova Iorque: McGraw-Hill, 2006.

[16] SEVERINO, A. Metodologia do trabalho científico. 23. ed. São Paulo: Cortez, 2007.

[17] SMELTZER, S. C. et al. Tratado de enfermagem médico-cirúrgica. 12. ed. Rio de Janeiro: Guanabara, 2012. v. 1.

[18] WITTER, G. P. Professor-estresse: análise de produção científica. Psicologia Escolar e Educação, Campinas, v. 7, n. 1, [n.p.], 2003.

Submetido em 04 nov. 2019

Aceito em 15 abr. 2020 